\title{
Film Cooling from Two Staggered Rows of Compound Angle Holes at High Blowing Ratios
}

\author{
PHILLIP M. LIGRANI \\ Convective Heat Transfer Laboratory, Department of Mechanical Engineering, University of Utah, Salt Lake City, Utah 84112 \\ JOON SIK LEE \\ Turbo and Power Machinery Research Center, Department of Mechanical Engineering, Seoul National University, Seoul 151-742, \\ Korea
}

\begin{abstract}
Experimental results are presented which describe the development and structure of flow downstream of two staggered rows of film-cooling holes with compound angle orientations at high blowing ratios. These film cooling configurations are important because they are frequently employed on the first stage of rotating blades of operating gas turbine engines. With this configuration, holes are spaced $3 \mathrm{~d}$ apart in the spanwise direction, with inclination angles of 24 degrees, and angles of orientation of 50.5 degrees. Blowing ratios range from 0.5 to 4.0 and the ratio of injectant to freestream density is near 1.0 . Results show that spanwise averaged adiabatic effectiveness, spanwise-averaged iso-energetic Stanton number ratios, surveys of streamwise mean velocity, and surveys of injectant distributions change by important amounts as the blowing ratio increases. This is due to injectant lift-off from the test surface just downstream of the holes which becomes more pronounced as blowing ratio increases.
\end{abstract}

Key Words: Gas turbines; film cooling; compound angle holes; turbine blades; film effectiveness

\section{INTRODUCTION}

$\mathrm{F}$ ilm holes with compound angle orientations are inclined to the test surface so that the coolant is ejected with a spanwise velocity component relative to the mainstream flow. Simple angle holes produce coolant without spanwise velocity components. Film holes with compound angle orientations are often used in place of simple angle holes because they are believed to produce injectant distributions over surfaces which give better protection and higher film effectiveness values. The results in this paper address the behavior of film cooling from compound angle holes at blowing ratios ranging from 0.5 to 4.0 .

Other investigations of film cooling from holes with compound angle orientations are described by Mayle and Camarata (1975), Kim et al. (1978), Mehendale and Han (1991), Ligrani et al. (1992, 1994a, 1994b), Sen et al. (1994), Schmidt et al. (1994), and Ekkad et al. (1995a, 1995b). Of these, Mayle and Camarata (1975) studied the effects of hole spacing and blowing ratio on heat transfer and film effectiveness for a staggered-hole array.
The holes were angled 30 degrees to the plate surface in planes oriented 45 degrees from the flow direction. Spanwise spacings between holes were $8 \mathrm{~d}, 10 \mathrm{~d}$ and $14 \mathrm{~d}$. Higher values of effectiveness were measured downstream of the holes with the smaller spacings. Kim, Moffat and Kays (1978) investigated heat transfer to a full coverage, film-cooled surface with holes having the same angles as employed by Mayle and Camarata (1975). For one injection temperature and one blowing ratio, Kim et al. (1978) concluded that heat transfer coefficients downstream of the compound angle configuration were half as high as ones measured downstream of simple angle holes slanted 30 from the test surface. In a study of turbine vane leading edge heat transfer, Mehendale and Han (1991) employed compound angle holes angled 30 degrees to the surface in planes oriented 90 degrees from the flow direction. Ligrani et al. (1992, 1994a, 1994b) present results from a systematic investigation conducted to compare results from compound angle and simple angle film hole arrangements. From a comparison of spanwise averaged adiabatic effectiveness values, the compound angle injection configuration pro- 
vides significantly improved protection compared to the simple angle configuration for the same spanwise hole spacing, normalized streamwise location, and blowing ratio within 60 diameters of the injection holes. Sen et al. (1994), and Schmidt et al. (1994) compare adiabatic effectiveness and iso-energetic heat transfer coefficient ratio from three different hole arrangements, one simple angle, one compound angle, and one compound angle with diffusing expanded exit.

Other investigations of lateral film cooling injection from holes in spanwise/normal planes are described by Goldstein et al. (1970), Honami and Fukagawa (1987), Sathyamurthy and Patankar (1990), Honami et al. (1994), and Ligrani and Ramsey (1996). Compared to streamwise injection from simple angle holes, measurements from Goldstein et al. (1970) indicate that lateral injection produces more effective cooling because the film is located closer to the wall. Honami and Fukagawa (1987) describe temperature profiles, velocity profiles, and turbulence intensity profiles produced by streamwise and lateral injection over flat and concave curved surfaces. Sathyamurthy and Patankar (1990) predict lateral film cooling from single rows of holes spaced $3 \mathrm{~d}, 4 \mathrm{~d}$ and $5 \mathrm{~d}$ apart. According to these investigators, laterally injected films show almost no change in tendency to lift-off as blowing changes from 0.1 to 1.0. Honami et al. (1994) present surface temperature distributions, and surveys of time-averaged velocity and temperature over flow cross sections downstream of a row of lateral holes with $5 \mathrm{~d}$ spanwise spacing. A large scale asymmetric vortex is described on one side of the film distribution which becomes more asymmetric as the blowing ratio increases. Ligrani and Ramsey (1996) describe results from spanwise oriented holes spaced $3 \mathrm{~d}$ apart in the spanwise direction and inclined at 30 degrees from the test surface. Adiabatic effectiveness magnitudes are higher and lower than ones downstream of a compound angle configuration depending upon the blowing ratio and non-dimensional streamwise location.

The present paper gives results from compound angle film holes at blowing ratios which are higher than the ones presented in other earlier studies by Mayle and Camarata (1975), Kim et al. (1978), Mehendale and Han (1991), Ligrani et al. (1992, 1994a, 1994b), Sen et al. (1994), Schmidt et al. (1994), Ekkad et al. (1995a, 1995b), Goldstein et al. (1970), Honami and Fukagawa (1987), Sathyamurthy and Patankar (1990), Honami et al. (1994), and Ligrani and Ramsey (1996).

\section{EXPERIMENTAL APPARATUS AND PROCEDURES}

Details on the experimental apparatus and procedures are presented by Ligrani et al. (1992, 1994a, 1994b) and by Ligrani and Ramsey (1995). A brief summary is also included here.

\section{Wind Tunnel, Coordinate System and Injection System}

The wind tunnel is the same one used in the experiments of Ligrani, Ciriello and Bishop (1992). The facility is open-circuit and subsonic. A centrifugal blower is located at the upstream end, followed by a diffuser, a header containing a honeycomb and three screens, and then a 16 to 1 contraction ratio nozzle. The nozzle leads to the test section which is a rectangular duct $3.05 \mathrm{~m}$ long, $0.61 \mathrm{~m}$ wide, and $0.203 \mathrm{~m}$ high at its entrance with a top wall having adjustable height. The freestream velocity is $10 \mathrm{~m} / \mathrm{s}$ and the freestream turbulence intensity is quite low at approximately 0.13 percent $(13 / 100$ of one percent) based on the same velocity. The boundary layer is tripped using a $2 \mathrm{~mm}$ high spanwise uniform strip of tape near the nozzle exit. It is located $1.072 \mathrm{~m}$ upstream of the constant heat flux transfer surface front edge . A schematic of the test surface is shown in Figure 1. In regard to the coordinate system, $\mathrm{z}$ is the spanwise coordinate measured from the test section spanwise centerline, $\mathrm{X}$ is measured from the upstream edge of the boundary layer trip, and $y$ is measured normal to the test surface. $\mathrm{x}$ is measured from the downstream edge of the injection holes and generally presented as $\mathrm{x} / \mathrm{d}$. The total boundary layer thickness just downstream of the injection holes $(\mathrm{x} / \mathrm{d}=2.75)$ is $0.973 \mathrm{~cm}$ giving a thickness to hole diameter ratio of 1.03 . The ratios of momentum thickness to hole diameter and displacement thickness to

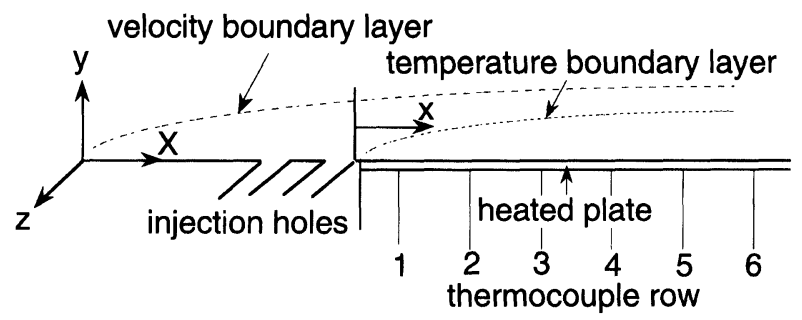

Figure 1. Schematic of test section and coordinate system. 
hole diameter at this location are then 0.13 and 0.22 , respectively.

The injection system is described by Ligrani, et al. (1992, 1994a, 1994b). With this system and test plate heating, the non-dimensional injection temperature parameter $\theta$ is maintained at values ranging from 0.0 to 3.0 , which includes values within the range of gas turbine component operation. The ratio of injectant to freestream density $\rho_{c} / \rho_{\infty}$ is from 0.94 to 1.00 . The upper surface of the plenum chamber is connected to the injection tubes of the different injection configurations, where each tube is about $7.6 \mathrm{~cm}$ long, giving a length to diameter ratio of about 8 .

\section{Stanton Number Measurements}

The heat transfer surface is also described by Ligrani et al. $(1992,1994 a, 1994 b)$. It is designed to provide a constant heat flux over its area using a surface next to the air stream which is stainless steel foil painted flat black. Immediately beneath this is a liner containing 126 thermocouples, which is just above an Electrofilm Corp. etched foil heater rated at 120 volts and 1500 watts. Located below the heater are several layers of insulating materials including Lexan sheets, foam insulation, Styrofoam and balsa wood. To determine the heat loss by conduction, an energy balance is performed. Radiation losses from the top of the test surface are analytically estimated. The thermal contact resistance between thermocouples and the foil top surface is based on a correlation dependent on heat flux through the foil, thermocouple readings and measurements from calibrated liquid crystals on the surface of the foil. Corrections to account for streamwise and spanwise conduction along the test surface are also employed using procedures developed and described by Wigle (1991).

Copper-constantan thermocouples are used to measure temperatures along the surface of the test plate and the freestream temperature. Voltages from thermocouples are digitally sampled and read using a Hewlett-Packard 3497A Data Acquisition Control Unit with a 3498A Extender. These units are controlled by a HewlettPackard Series 9000 Model 310 computer.

\section{Adiabatic Film Cooling Effectiveness Measurements}

Adiabatic film cooling effectiveness values are determined using linear superposition theory applied to Stanton number ratios measured at different injection temperatures. To do this, local adiabatic film effectiveness values are determined from measurements of local $\mathrm{St} / \mathrm{St}_{0}$ at different magnitudes of the non-dimensional injection temperature, $\theta$. The details of this approach are described by Ligrani et al. (1992, 1994a, 1994b), including a test to check the procedure using a direct $\eta$ measurement with a near adiabatic condition on the test plate. $\eta$ differences from the two techniques were always less than experimental uncertainties, which range from 0.01 to 0.03 effectiveness units (Ligrani and Ramsey, 1995).

This approach applies only so long as temperature variations are small enough that fluid properties are reasonably invariant as $\theta$ is changed, and as long as fluid properties are reasonably invariant with respect to all three coordinate directions (Ligrani et al., 1992). In addition, the three-dimensional energy equation which describes the flow field must be linear and homogeneous in its dependent variable, temperature. To meet these conditions, near constant property conditions are maintained throughout the boundary layer by employing low subsonic speeds and temperature differences which are less than 30 degrees Celcius.

\section{Baseline Data Checks}

Baseline data checks were made with no film cooling. Repeated measurements of spanwise-averaged Stanton numbers show good agreement (maximum deviation is 4 percent) with the correlation for turbulent heat transfer to a flat plate with unheated starting length and constant heat flux boundary condition. Ligrani et al. (1992, 1994a, 1994b) provide additional details.

\section{INJECTION CONFIGURATION}

A schematic drawing showing the film hole geometry is presented in Figure 2. Here, the hole arrangement along the test surface ( $\mathrm{x}-\mathrm{z}$ plane) is shown as seen in the negative y direction. In each case, holes are placed in two rows such that the holes are staggered with respect to each other. Each row contains five injection cooling holes arranged so that the centerline of the middle hole in the downstream row is located on the spanwise centerline $(\mathrm{z}=0.0 \mathrm{~cm})$ of the test surface.

The present injection configuration is designated by Ligrani et al. (1992, 1994a, 1994b) as configuration 3. 
Figure 2 shows that the spanwise spacings between adjacent holes is $3.0 \mathrm{~d}$, and centerlines of holes in separate rows are separated by $4.0 \mathrm{~d}$ in the streamwise direction. Hole diameter $d$ is $0.925 \mathrm{~cm}$. Compound angle holes are employed with $\Omega=35$ degrees and $\beta=30$ degrees, where $\Omega$ is the angle of the injection holes with respect to the test surface as projected into the streamwise/normal plane, and $\beta$ is the angle of the injection holes with respect to the test surface as projected into the spanwise/normal plane. Thus, holes are oriented so that the spanwise components of injectant velocity are directed in the negative $\mathrm{z}$ direction. The hole inclination angle is then 24 degrees, and the angle of orientation is 50.5 degrees. This means that the plane of each injection hole is angled at 50.5 degrees from the streamwise/normal (x-y) plane, and, within the plane of each hole, hole centerlines are oriented at angles of 24 degrees from the plane of the test surface $(x-z)$.

\section{EXPERIMENTAL RESULTS}

Measurements downstream of the compound angle film cooling holes are discussed in this section. These include distributions of adiabatic film cooling effectiveness, distributions of iso-energetic Stanton number ratios, surveys of streamwise mean velocity, and surveys of injectant distributions.

\section{Spanwise-Averaged Adiabatic Film Cooling Effectiveness}

Spanwise-averaged magnitudes of effectiveness and Stanton number are determined from local measurements of these quantities for each thermocouple row by averaging the first 13 data points from each row over a $\mathrm{z} / \mathrm{d}$ range from -13.7 to 2.7 . These spanwise locations are used because the spanwise trajectory of the film causes the film to move in the negative $\mathrm{z}$ direction after it exits the injection holes. This results in regions with little film coverage on the downstream portions of the test surface at $\mathrm{z} / \mathrm{d}>2.7$.

Spanwise-averaged values of the adiabatic film cooling effectiveness measured downstream of configuration 3 compound angle holes are presented in figure 3 . Results are given at $\mathrm{x} / \mathrm{d}$ of $6.8,17.6,33.8,55.5,77.1$, and 98.7.

The adiabatic effectiveness data in Figure 3 for blowing ratios of $0.5,1.0$ and 1.5 are now discussed. At $x / d$ less than 20 , values decrease with blowing ratio because of the lift off of injectant from the test surface. However, as the boundary layers advect farther downstream, $\bar{\eta}$ values for $m=0.5$ are lower than values for $m=1.0$ and $\mathrm{m}=1.5$ since a smaller amount of film is spread along the test surface. These differences also result partially because of the different ways in which the injectant spreads along the test surface. When $\mathrm{m}=0.5$, the injectant is fairly uniform along the test surface, especially for $\mathrm{x} / \mathrm{d}>40$. However, at the higher blowing ratios greater than or equal to 1.0 , the injectant from an individual hole in the upstream row of holes coalesces with the injectant from the nearest individual hole in the downstream row of holes (Ligrani et al., 1994a, 1994b). This results in adiabatic effectiveness distributions which are spatially non-uniform across the test surface span at $\mathrm{x} / \mathrm{d}$ as large as 98.7 . As a result, increasing the blowing ratio from 0.5 to 1.5 gives little increase in film protection from the holes in the upstream row because little film from these holes is near the test surface. This is

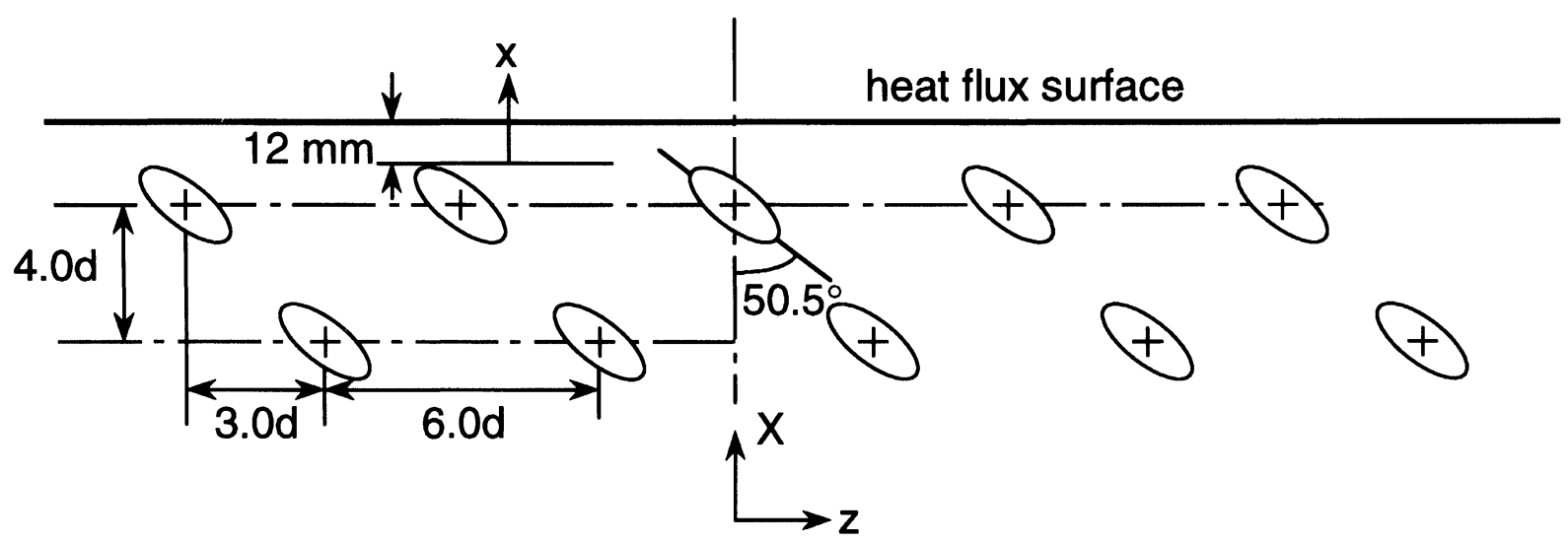

Figure 2. Test surface injection geometry for film cooling holes arranged with configuration 3 compound angle holes. 


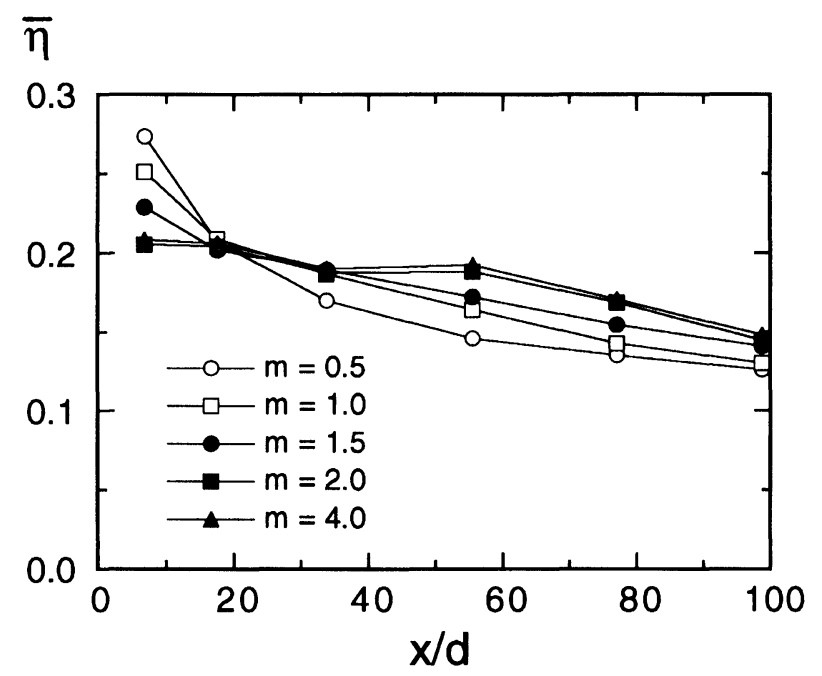

Figure 3. Spanwise-averaged magnitudes of adiabatic film cooling effectiveness as dependent upon normalized streamwise distance downstream of two rows of compound angle configuration 3 film cooling holes.

probably one reason why spanwise-averaged effectiveness values for $\mathrm{m}=1.0$ and $\mathrm{m}=1.5$ are so close together for $\mathrm{x} / \mathrm{d}>20$.

According to Ligrani, Ciriello and Bishop (1992), lift-off of the injectant from two rows of compound angle holes (with $3.9 \mathrm{~d}$ spanwise spacing) is probably occurring at momentum flux ratios between 1.0 and 2.0. The present data for $3.0 \mathrm{~d}$ spanwise spacing show similar behavior. In contrast, the simple angle configuration show significant decreases of effectiveness as momentum flux increases from 0.25 to 1.0 indicating lift-off at a lower value of momentum flux (Ligrani et al., 1994a). These differences result, first of all, because the lateral component of momentum of the injectant from the compound angle holes causes the injectant to spread out much more in the lateral direction as it is advected downstream and penetrates into the mainstream. Second, the hole angles with respect to the test surface are 24 degrees for the compound angle arrangement compared to 35 degrees for the simple angle arrangement.

Adiabatic effectiveness data at blowing ratios from 1.5 to 4.0 are now discussed. Figure 3 shows that spanwiseaveraged effectiveness magnitudes for $\mathrm{m}=2.0$ and $\mathrm{m}=$ 4.0 are lower than ones obtained at lower blowing ratios at $\mathrm{x} / \mathrm{d}=6.8$. As for the data at lower $\mathrm{m}$, this is also believed to be a consequence of lift-off of the injectant from the test surface. At $\mathrm{x} / \mathrm{d}=17.6$, effectiveness magnitudes are about the same for all five blowing ratios. At locations farther downstream, spanwise-averaged values then increase with blowing ratio at particular $\mathrm{x} / \mathrm{d}$ locations as more injectant is present along the test surface. However, changes as blowing ratio increases from 2.0 to 4.0 are generally quite small. Surveys of streamwise mean velocity and injectant distributions from Wigle (1991) indicate that differences in injectant lift-off, merging, coalescence, and spreading along the test surface are responsible.

\section{Spanwise-Averaged Iso-Energetic Stanton Number Ratios}

Spanwise-averaged iso-energetic Stanton number ratios are given in Figure 4. Several interesting trends are apparent for each blowing ratio. First, $\overline{\mathrm{S} t_{f} / \mathrm{S} t_{o}}$ values for all blowing ratios for all $\mathrm{x} / \mathrm{d}$ are greater than 1.0. Second, little $\overline{\mathrm{S} t / \mathrm{S} t_{o}}$ variation with $\mathrm{x} / \mathrm{d}$ is evident for each value of $\mathrm{m}$. Third, for each $\mathrm{x} / \mathrm{d}, \overline{\mathrm{S} t_{f} / \mathrm{S} t_{o}}$ values generally increase with $\mathrm{m}$.

As blowing ratio increases from 0.5 to $1.5, \overline{\mathrm{S} t_{f} / \mathrm{St} t_{o}}$ data in Figure 4 range between 1.0 and 1.2. $\overline{\mathrm{S} t_{f} / \mathrm{S} t_{o}}$ values for $\mathrm{m}=2.0$ are about the same as $\overline{\mathrm{S} t_{f} / \mathrm{St} t_{o}}$ values for $\mathrm{m}=4.0$ at each $\mathrm{x} / \mathrm{d}$, and are considerably higher than ones measured at lower $\mathrm{m}$. These increased magnitudes are most likely due to increased turbulence and mixing as the film emerges from the film cooling holes and is then swept and turned in the direction of the mainstream.

\section{Surveys of Streamwise Mean Velocity}

Surveys of streamwise mean velocity measured at $\mathrm{x} / \mathrm{d}=$ 9.9 are presented in Figure 5 for blowing ratios of 1.5,

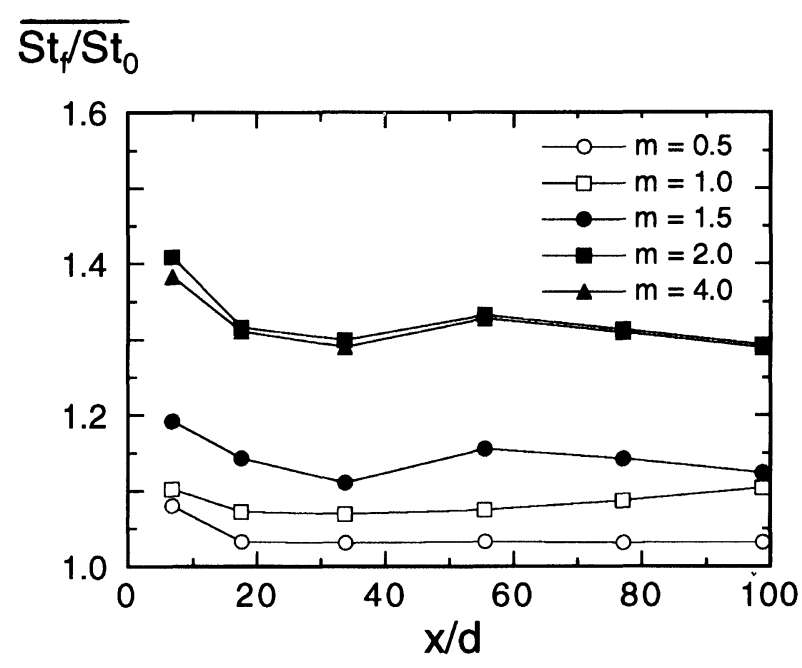

Figure 4. Spanwise-averaged magnitudes of iso-energetic Stanton number ratio as dependent upon normalized streamwise distance downstream of two rows of compound angle configuration 3 film cooling holes. 
$y / d$
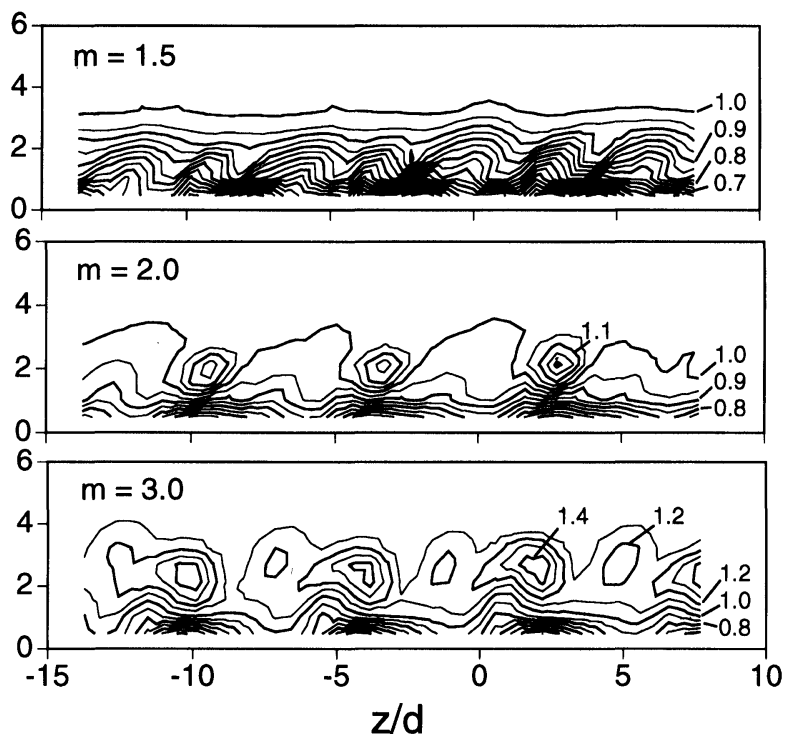

Figure 5. Streamwise mean velocity distributions measured downstream of two rows of compound angle configuration 3 holes at $\mathrm{x} / \mathrm{d}=$ 9.9 for $\mathrm{m}=1.5,2.0$, and 3.0 .

2.0, and 3.0. In each case, contour levels of local streamwise mean velocity normalized by the freestream mean velocity, $\mathrm{U} / \mathrm{U}_{\infty}$, are given.

At $m=1.5$, velocity deficits in Figure 5 are skewed and flattened with the largest velocity gradients at $y / d$ ranging from 0.5 to 2.0 which appear to be largest in the direction that film is ejected from the surface. Because of the negative spanwise components of velocity at the exits of the film holes, deficits are also displaced $-2.0 \mathrm{~d}$ to $-2.5 \mathrm{~d}$ by the time they reach $\mathrm{x} / \mathrm{d}=9.9$. Here, every other deficit is different such that deficits from holes in the upstream row of holes are smaller than ones from holes in the downstream row. As the $\mathrm{m}=1.5$ film cooled boundary layer advects downstream, results from Wigle (1991) show that deficits resulting from injection from the downstream row of holes persist, whereas injectant deficits from the upstream row of holes become less apparent. This occurs because injectant from upstream holes eventually merges and coalesces with injectant which originated from holes in the downstream row. Consequently, half as many velocity deficits are eventually present across the measurement plane at $\mathrm{x} / \mathrm{d}$ of 44.3 and 86.3 compared to results at the $\mathrm{x} / \mathrm{d}=9.9$ location (Wigle, 1991). Similar behavior are observed at $\mathrm{m}=1.0$ (Ligrani et al., 1994a).

Figure 5 shows that injectant from individual holes in the upstream row has merged with injectant from adjacent holes in the downstream row at $\mathrm{m}=2.0$ and $\mathrm{m}=$
3.0 for $\mathrm{x} / \mathrm{d}=9.9$. However, instead of streamwise mean velocity deficits, local $\mathrm{U} / \mathrm{U}_{\infty}$ maxima evidence film concentrations since blowing ratios are considerably greater than 1.0. This results in local $\mathrm{U} / \mathrm{U}_{\infty}$ values greater than 1.2 for $\mathrm{m}=2.0$ and greater than 1.4 for $\mathrm{m}=3.0$ at $\mathrm{x} / \mathrm{d}=9.9$ in spite of considerable injectant advection and diffusion between this location and $\mathrm{x} / \mathrm{d}=0$. The local $\mathrm{U} / \mathrm{U}_{\infty}$ maxima are also located considerably away from the test surface, evidencing strong lift-off of the film at these high blowing ratios. For $\mathrm{m}=2.0$, local $\mathrm{U} / \mathrm{U}_{\infty}$ maxima are located near $y / d=2.0$, and for $\mathrm{m}=3.0$, local $\mathrm{U} / \mathrm{U}_{\infty}$ maxima are located at $\mathrm{y} / \mathrm{d}$ between 2.0 and 3.0 .

\section{Surveys of Injectant Distributions}

Injection distribution surveys measured downstream of the compound angle injection holes are presented in Figure 6 for blowing ratios of 1.5, 2.0, and 3.0. These

$y / d$
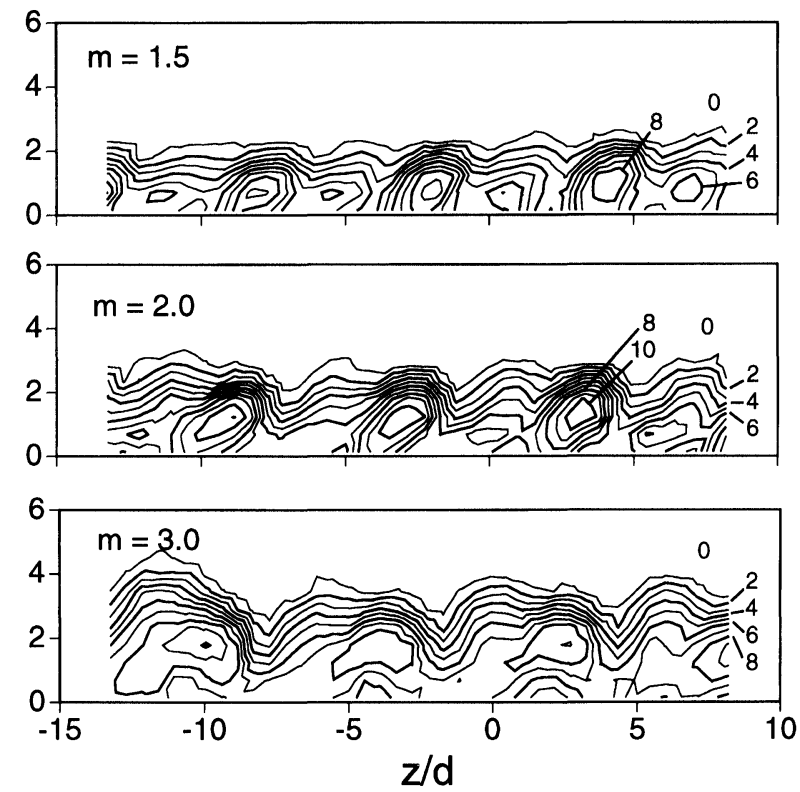

Figure 6. Mean temperature fields showing distributions of film injectant measured downstream of two rows of compound angle configuration 3 holes at $\mathrm{x} / \mathrm{d}=9.9$ for $\mathrm{m}=1.5,2.0$, and 3.0.

$\begin{array}{llll}\left(\mathrm{T}_{\mathrm{r}}-\mathrm{T}_{\mathrm{r}, \infty}\right)\left({ }^{\circ} \mathrm{C}\right) & \text { CONTOUR LEVELS } \\ 0 & <0.5 & 6 & 5.0-6.0 \\ 1 & 0.5-1.0 & 7 & 6.0-7.0 \\ 2 & 1.0-2.0 & 8 & 7.0-8.0 \\ 3 & 2.0-3.0 & 9 & 8.0-9.0 \\ 4 & 3.0-4.0 & 10 & >9.0\end{array}$


distributions are obtained using procedures described by Ligrani et al. (1989) in which the injectant is heated without providing any heat to the test plate. With this approach, the injectant is the only source of thermal energy relative to the freestream flow. Distributions of $\left(T_{r}-T_{r, \infty}\right)$, such as the ones in Figure 6, thus show how injectant accumulates and is rearranged in the boundary layer by advection including any secondary flows which may be present. Thus, the temperature field is employed here to show injectant distributions in the spanwise/ normal plane at $\mathrm{x} / \mathrm{d}=9.9$.

In Figure 6, skewed and lop-sided injectant concentrations are evident in the spanwise/normal plane at $\mathrm{x} / \mathrm{d}$ $=9.9$ for $\mathrm{m}=1.5, \mathrm{~m}=2.0$, and $\mathrm{m}=3.0$ where accumulations from the downstream row of holes cover larger portions of the measurement plane than accumulations from the upstream row of holes. Each accumulation from an individual hole in the downstream row of holes is also in close proximity with the accumulation from the nearest hole in the upstream row. This is evidenced for $\mathrm{x} / \mathrm{d}=9.9$ in Figure 6 , in particular for $\mathrm{m}$ $=1.5$ and $\mathrm{m}=2.0$, by connected regions of injectant concentration in the spanwise/normal plane for each pair of holes. Between these concentrations, well defined deficits of injectant are evident which closely correspond with $\eta$ minima (Wigle, 1991; Ligrani et al., 1994a). With streamwise advection to $\mathrm{x} / \mathrm{d}$ of 44.3 and 86.3 , injectant accumulations become more diffuse and dissipated (Wigle, 1991; Ligrani et al., 1994a). In addition, the injectant concentrations from the upstream row of holes completely merge with the concentrations from the downstream row of holes resulting in half as many accumulations across the span of the measurement plane at $\mathrm{x} / \mathrm{d}$ of 44.3 and 86.3 compared to $\mathrm{x} / \mathrm{d}=9.9$.

The behavior shown in Figure 6 is consistent with the velocity surveys shown in Figure 5, since injectant accumulations for all three $\mathrm{m}$ show close correspondence to streamwise velocity deficits or streamwise mean velocity local maxima. One injectant accumulation is present for each velocity local maxima or local minima such that accumulations generally lie just to the right (at larger Z) of streamwise velocity deficits.

Another interesting feature of the results in Figure 6 are the spanwise locations of the film concentrations, which are located at smaller $\mathrm{z} / \mathrm{d}$ from individual film holes as $\mathrm{m}$ increases. In addition, the injectant distributions surveys in Figure 6 are consistent with the velocity surveys in Figure 5 since the largest injectant concentrations are also located considerably away from the test surface, evidencing strong lift-off of the film. This is especially true for $\mathrm{m}=2.0$ and $\mathrm{m}=3.0$. For $\mathrm{m}=2.0$, the largest injectant concentrations are located at $y / d$ between 1.5 and 2.0, and for $\mathrm{m}=3.0$, the largest injectant concentrations are located at $\mathrm{y} / \mathrm{d}$ between 1.5 and 2.5 .

\section{SUMMARY AND CONCLUSIONS}

Experimental results are presented which describe the development and structure of flow downstream of two staggered rows of film-cooling holes with compound angle orientations at blowing ratios ranging from 0.5 to 4.0. With this configuration, which is denoted number 3 , holes are spaced 3d apart in the spanwise direction with inclination angles of 24 degrees, and orientation angles of 50.5 degrees. Results are presented for an injectant to freestream density ratio near 1.0 , and $\mathrm{x} / \mathrm{d}$ ranging from 6.8 to 98.7 .

Spanwise-averaged values of the adiabatic film cooling effectiveness measured downstream of configuration 3 at $x / d=6.8$ are highest with a blowing ratio of 0.5 , and decrease with blowing ratio because of injection jet lift-off effects for . Lift-off at $\mathrm{m}=1.5, \mathrm{~m}=2.0$, and $\mathrm{m}$ $=3.0$ is confirmed by injection distribution surveys which also show that injectant from an individual hole in the upstream row coalesces with the injectant from the closest hole in the downstream row. This produces spanwise periodic concentrations of injectant and local protection at $\mathrm{x} / \mathrm{d}=6.8$. As the boundary layers advect farther downstream to $\mathrm{x} / \mathrm{d}>20, \bar{\eta}$ values increase with $\mathrm{m}$ since larger amounts of film are spread along the test surface.

Spanwise-averaged iso-energetic Stanton number ratios range between 1.0 and 1.42. $\overline{\mathrm{S} t_{f} / \mathrm{S} t_{o}}$ values increase with $\mathrm{m}$ at each $\mathrm{x} / \mathrm{d}$, and show little variation with $\mathrm{x} / \mathrm{d}$ for each value of $m$ tested. At particular $x / d$ locations, the highest $\overline{\mathrm{S} t_{f} / \mathrm{S} t_{o}}$ are measured at $\mathrm{m}=2.0$ and $\mathrm{m}=4.0$ due to higher boundary layer mixing and turbulence as the film emerges from the holes and is swept and turned in the direction of the mainstream.

$\begin{array}{ll}\text { Nomenclature } & \\ d & \text { injection hole diameter } \\ m & \text { blowing ratio, } \rho_{\mathrm{c}} \mathrm{U}_{\mathrm{c}} / \rho_{\infty} \mathrm{U}_{\infty} \\ S t & \text { Stanton number with film injection } \\ S t_{o} & \text { baseline Stanton number, no film injection } \\ S t_{f} & \text { iso-energetic Stanton number with film } \\ \overline{\mathrm{S} t_{f}} & \text { injection } \\ & \text { spanwise-averaged iso-energetic Stanton } \\ T & \text { number with film injection } \\ U & \text { temperature } \\ X, x & \text { velocity } \\ y & \text { streamwise distance }\end{array}$


$z \quad$ spanwise distance from test surface centerline

$\eta \quad$ adiabatic film cooling effectiveness, $\left(\mathrm{T}_{\mathrm{aw}}-\mathrm{T}_{\mathrm{r}}\right.$,

$\infty) /\left(\mathrm{T}_{\mathrm{r}, \mathrm{c}}-\mathrm{T}_{\mathrm{r}, \infty}\right)$

$\bar{\eta} \quad$ spanwise-averaged adiabatic film cooling

$\theta \quad$ non-dimensional injection temperature, $\left(\mathrm{T}_{\mathrm{r}, \mathrm{c}}\right.$ $\left.\mathrm{T}_{\mathrm{r}, \infty}\right) /\left(\mathrm{T}_{\mathrm{w}}-\mathrm{T}_{\mathrm{r}, \infty}\right)$

$\Omega \quad$ injection hole angle with respect to the test surface as projected into the streamwise/normal plane

$\beta \quad$ injection hole angle with respect to the test surface as projected into the spanwise/normal plane

$\rho$ density

\section{subscripts}

aw

$c$

$o$

$r$

$w$

$\infty$

superscripts

m

spanwise average

\section{References}

Ekkad S. V., Zapata D., and Han J.-C. Heat Transfer Coefficients Over a Flat Surface With Air and $\mathrm{CO}_{2}$ Injection Through Compound Angle Holes Using a Transient Liquid Crystal Image Method, accepted for publication in the ASME Transactions Journal of Turbomachinery, 1995a.

Ekkad S. V., Zapata D., and Han J.-C. Film Effectiveness Over a Flat Surface With Air and $\mathrm{CO}_{2}$ Injection Through Compound Angle Holes Using a Transient Liquid Crystal Image Method, accepted for publication in the ASME Transactions Journal of Turbomachinery, $1995 \mathrm{~b}$.

Goldstein R. J., Eckert E. R. G., Eriksen V. L., and Ramsey J. W. Film Cooling Following Injection Through Inclined Circular Tubes, Israel Journal of Technology, Vol. 8, pp. 145-154, 1970.

Honami S., and Fukagawa M. A Study on Film Cooling Behavior of a Cooling Jet Over a Concave Surface, Paper No. 87-Tokyo IGTC-72, Proceedings of the 1987 Tokyo International Gas Turbine Congress, Vol. 3, pp. 209-216, 1987.

Honami S., Shizawa T., and Uchiyama A. Behavior of the Laterally Injected Jet in Film Cooling: Measurements of Surface Temperature

and Velocity/Temperature Field Within the Jet, ASME TransactionsJournal of Turbomachinery, Vol. 116, No. 1, pp. 106-112, 1994.

Kim H. K., Moffat R. J., and Kays W. M. Heat Transfer to a Full-Coverage, Film-Cooled Surface With Compound-Angle $\left(30^{\circ}\right.$ and $45^{\circ}$ ) Hole Injection, Report HMT-28, Thermosciences Division, Department of Mechanical Engineering, Stanford University, Stanford, Ca., 1978.

Ligrani P. M., Ciriello S., and Bishop D. T. Heat Transfer, Adiabatic Effectiveness, and Injectant Distributions Downstream of a Single Row and Two Staggered Rows of Compound Angle Film-Cooling Holes, ASME Transactions-Journal of Turbomachinery, Vol. 114, No. 4, pp. 687-700, 1992

Ligrani P. M., Ortiz A., Joseph S. L., and Evans D. L. Effects of Embedded Vortices on Film-Cooled Turbulent Boundary Layers, ASME Transactions-Journal of Turbomachinery, Vol. 111, No. 1, pp. 71-77, 1989.

Ligrani P. M., and Ramsey A. E. Film Cooling From Spanwise Oriented Holes in Two Staggered Rows, accepted for publication in the ASME Transactions-Journal of Turbomachinery, 1996.

Ligrani P. M., Wigle J. M., Ciriello S., and Jackson S. M. Film Cooling From Holes With Compound Angle Orientations, Part 1: Results Downstream of Two Staggered Rows of Holes With 3d Spanwise Spacing, ASME Transactions-Journal of Heat Transfer, Vol. 116, No. 2, pp. 341-352, 1994a.

Ligrani P. M., Wigle J. M., and Jackson S. M. Film Cooling From Holes With Compound Angle Orientations, Part 2: Results Downstream of a Single Row of Holes With 6d Spanwise Spacing, ASME Transactions-Journal of Heat Transfer, Vol. 116, No. 2, pp. 353-362, $1994 \mathrm{~b}$.

Mayle R. E., and Camarata F. J. Multihole Cooling Film Effectiveness and Heat Transfer, ASME Transactions-Journal of Heat Transfer, Vol. 97, pp. 534-538, 1975.

Mehendale A. B., and Han J. C. Influence of High Mainstream Turbulence on Leading Edge Film Cooling Heat Transfer, ASME Transactions-Journal of Turbomachinery, Vol. 114, No. 4, pp. 707-715, 1992.

Sathyamurthy P., and Patankar S. V. Prediction of Film Cooling With Lateral Injection, ASME-HTD Vol. 138, Heat Transfer in Turbulent Flows, pp. 61-70, 1990.

Schmidt D. L., Sen B., and Bogard D. G. Film Cooling With Compound Angle Holes: Adiabatic Effectiveness, Paper No. 94-GT312, ASME International Gas Turbine and Aeroengine Congress and Exposition, The Hague, Netherlands, June 13-16, 1994.

Sen B., Schmidt D. L., and Bogard D. G. Film Cooling With Compound Angle Holes: Heat Transfer, Paper No. 94-GT-311, ASME International Gas Turbine and Aeroengine Congress and Exposition, The Hague, Netherlands, June 13-16, 1994.

Wigle J. M. Heat Transfer, Adiabatic Effectiveness and Injectant Distributions Downstream of Single and Double Rows of FilmCooling Holes with Compound Angles, M. S. Thesis, Department of Mechanical Engineering, Naval Postgraduate School, Monterey, 1991. 

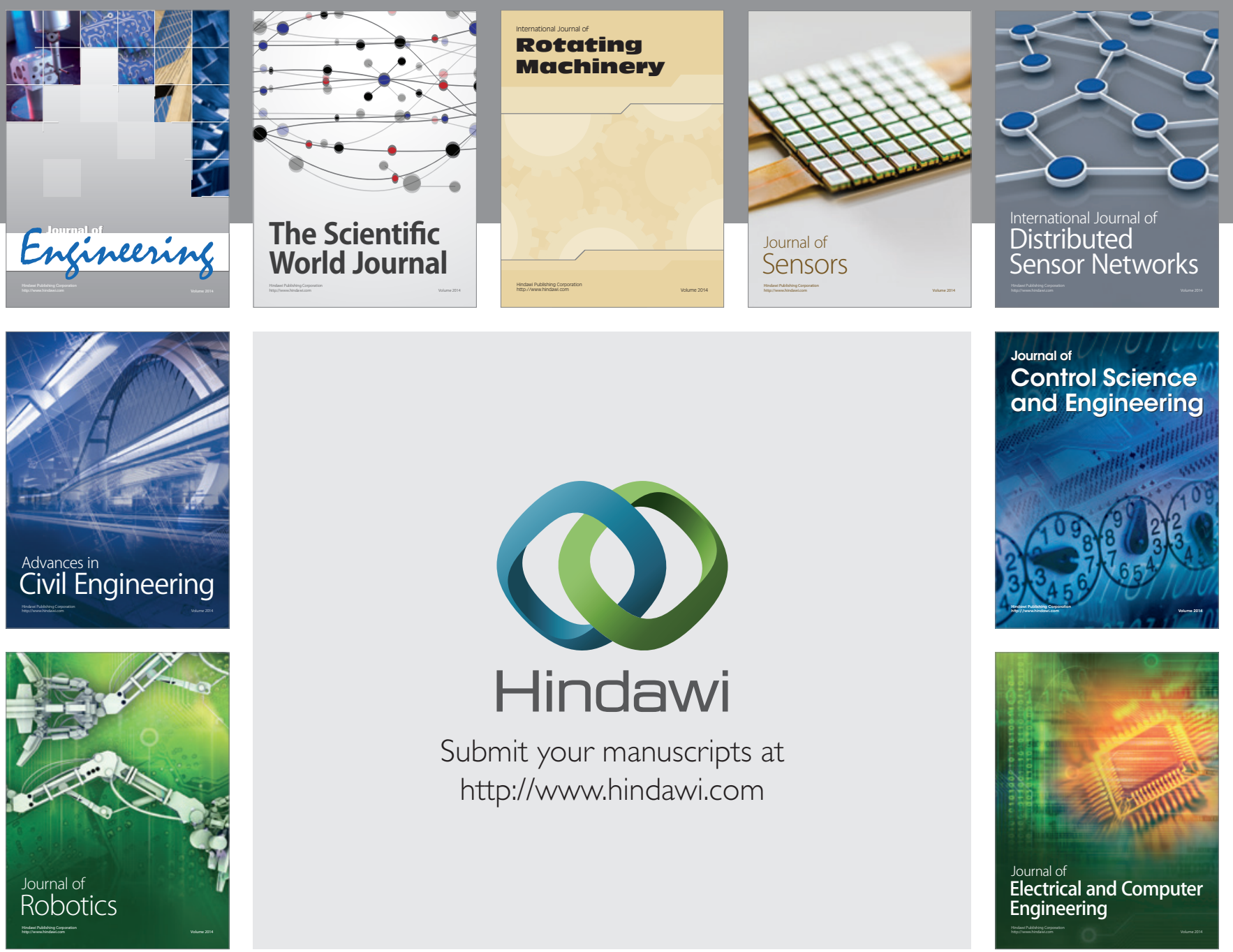

Submit your manuscripts at

http://www.hindawi.com
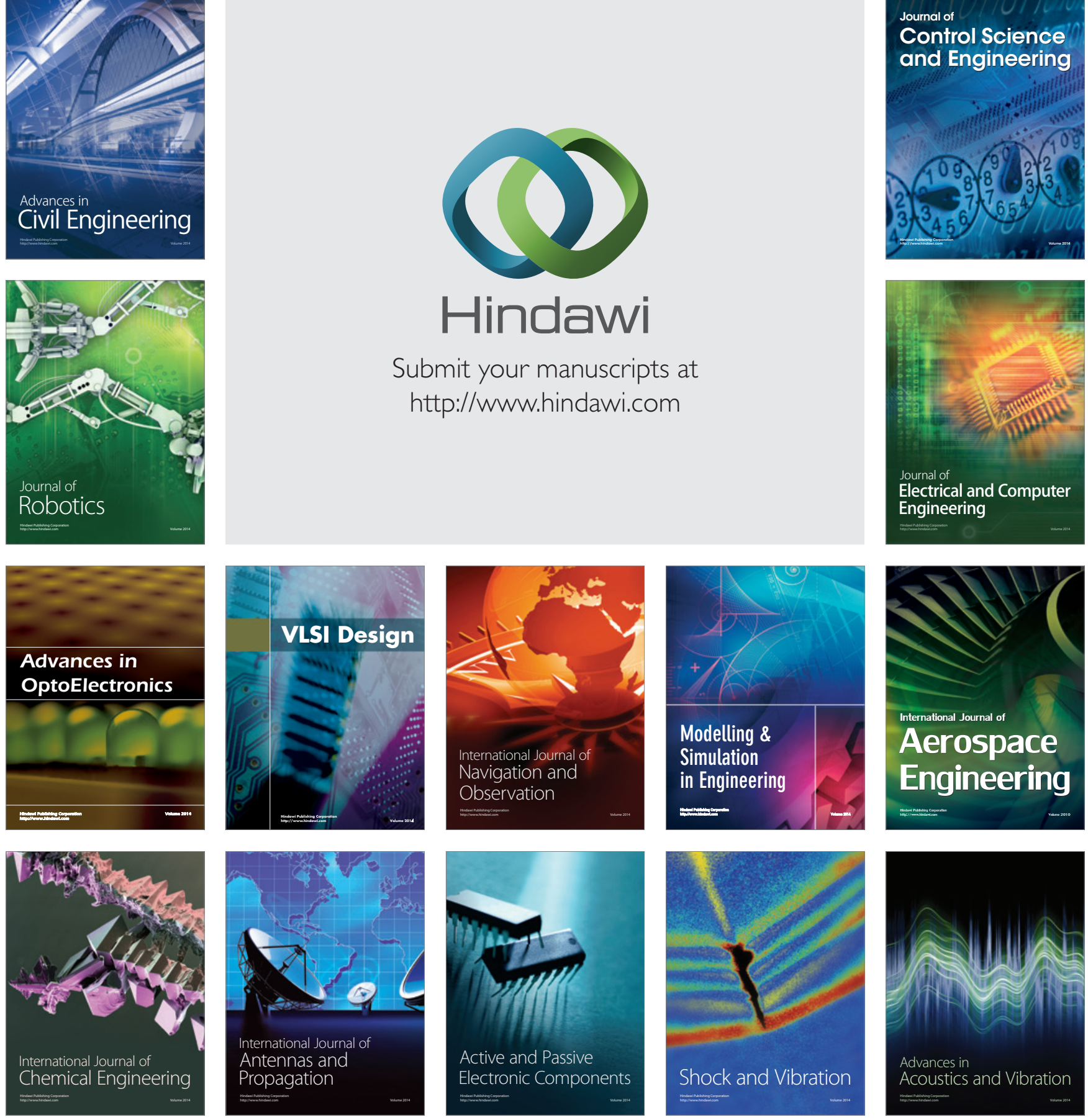